\section{Nephrology}

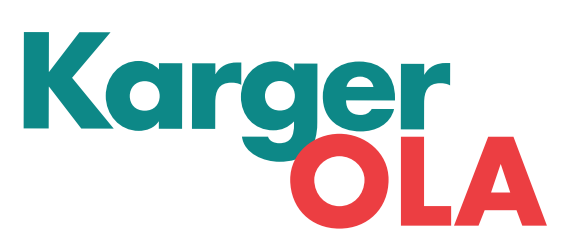

Am J Nephrol 2014;40:391

DOI: 10.1159/000367865
Published online: October 29, 2014

\title{
KARGER-OLA MONTHLY BLOGS
}

Karger Publishers, publisher of leading nephrology journals, and the Global Kidney Academy (GKA), a nephrology education organization, have come together to offer nephrologists worldwide an incredible learning and exchange opportunity.

Karger and the GKA's On Line Academy (OLA) launched Karger-OLA ((http://www.gkaonlineacademy. com/karger)) in 2013, free of charge for all readers. The Karger OLA blogs provide free access every month to top articles selected by the editors of journals from the World of Nephrology at Karger.com ((https://www.karger.com/ nephrology)). The posts include analysis by Prof. Richard Glassock, an internationally renowned nephrologist, academician, teacher and researcher, currently Emeritus Professor at the Geffen School of Medicine at UCLA. Prof. Glassock's expertise provides a huge benefit as he turns a critical eye to topical issues raised by the latest articles and gives readers the opportunity to comment back and engage in open discussion. Karger-OLA also gives the floor to the articles' authors so they can interact with their peers and, in turn, the readers can engage with the authors. By selecting recent publications of global interest to nephrology practitioners worldwide, Karger-OLA blogs aim to educate and challenge nephrologists from all stages of their careers to consider new perspectives on important topics in both clinical and basic research.

This century's sea change in education has been driven by network learning and global access to the Internet as well as social media and interactive learning. Continuous Nephrological Education (CNE) has evolved so that ne- phrologists can now expand their knowledge from home. The GKA has been at the forefront of this revolution in the field of nephrology. GKA's OLA has attracted thousands of nephrologists and created one of the largest interactive learning networks in the field. The Karger-OLA initiative was founded in that spirit and has proven a great success, continually attracting more participants.

We invite nephrologists around the world to take advantage of this exciting portal to broaden their knowledge of nephrology and join the discussion. Make the most of this golden learning opportunity and join Karger-OLA.

https://www.gkaonlineacademy.com/Karger.

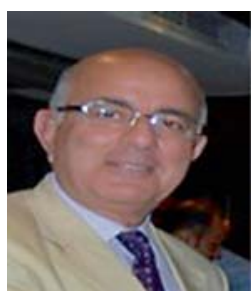

Prof. Meguid El Nahas, MD, PhD, FRCP Chairman Global Kidney Academy

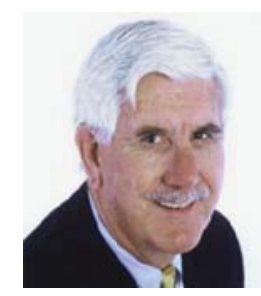

Prof. Richard Glassock, MD Karger OLA Chief Editor, OLA Contributor

\section{KARGER}

E-Mail karger@karger.com www.karger.com/ajn
(C) 2014 S. Karger AG, Basel

0250-8095/14/0404-0391\$39.50/0 